\title{
FITOSSANIDADE
}

\section{RESISTÊNCIA INDUZIDA AO PULGÃO-GIGANTE-DO-PINUS (HEMIPTERA: APHIDIDAE) EM PLANTAS DE PINUS TAEDA ADUBADAS COM SILÍCIO ( ${ }^{1}$ )}

\author{
JOELMA MELISSA MALHERBE CAMARGO $\left({ }^{*}\right)$; JAIR CAMPOS MORAES $\left({ }^{3}\right)$; EDILSON BATISTA \\ DE OLIVEIRA $\left({ }^{4}\right)$; EDSON TADEU IEDE $\left({ }^{4}\right)$
}

\begin{abstract}
RESUMO
Este trabalho objetivou avaliar o efeito da aplicação de silício na indução de resistência de Pinus taeda L. ao pulgão-gigante-do-pinus Cinara atlantica (Wilson). Foram realizados testes com chance de escolha em plantas com e sem aplicação de silício, onde foi avaliada a preferência e a capacidade reprodutiva dos afídeos. Os testes foram realizados em laboratório (T: $20^{\circ} \mathrm{C}$; UR: 70\%; fotofase: 12 horas), em delineamento experimental inteiramente casualizado, com três tratamentos e dez repetições. Os tratamentos foram: T1 - (sem aplicação de silício); T2 - uma dose de 0,01g de silício e T3 - quatro doses de 0,01g de silício, com intervalos de cinco dias entre as aplicações. As aplicações das doses foram via solo. Vinte dias após a aplicação, realizaram-se os testes de preferência e de capacidade reprodutiva com chance de escolha, utilizando-se como arena placas de Petri com ramos de pinus e gaiolas de PVC com mudas de pinus em tubetes. Em cada arena foram liberados 20 pulgões adultos. As avaliações em placas de Petri foram realizadas aos 40 e 90 minutos e às 4, 12, 18, 24, 36, 48 e 72 horas após a liberação dos insetos; em gaiolas as avaliações foram realizadas no primeiro, segundo, terceiro, quarto e sétimo dia, estendendo-se este período por mais três semanas. A aplicação de silício influenciou negativamente a preferência e a capacidade reprodutiva de C. atlantica.
\end{abstract}

Palavras-chave: Cinara atlantica, pinus, silício, não-preferência, manejo integrado de pragas.

\section{ABSTRACT \\ INDUCED RESISTANCE EFFECT TO THE GIANT CONIFER APHID (HEMIPTERA:APHIDIDAE) IN SILICON FERTILIZED PLANTS OF PINUS TAEDA}

This research aimed to study the effect of silicon as a resistance inducer in P. taeda L. to C. atlantica (Wilson). Preference and reproductive rate tests were performed in plants of $P$. taeda with and without silicon application. The experiment was carried out in controlled environmental chamber (T: $20^{\circ} \mathrm{C}$; UR: $70 \%$; fotofase: $12 \mathrm{~h}$ ), in a completely random design, and consisted of three treatments and ten replications. The treatments were: T1- substratum standard (without silicon application), T2 - substratum standard + one dose of 0,01g de silicon, T3 - substratum standard + four doses of $0,01 \mathrm{~g}$ de silicon, with intervals of five days between the applications. Twenty days after the application, a free choice preference test was performed in two different arenas: Petri dishes with pine branches and PVC cages with pine seedlings. Twenty adult aphids were released in each arena. Petri dishes were observed at 40 and 90 minutes, then 4, 12, 18, 24, 36 and 72 hours after release. Pine seedlings in PVC cages were examined in the first, second, third, fourth and seventh days, followed by a weekly record on the next three weeks. Silicon application showed a negative response to preference and reproductive capacity in adults of $C$. atlantica.

Key words: Cinara atlantica, pinus, silicon, non-preference.

$\left({ }^{1}\right)$ Recebido para publicação em 22 de novembro de 2006 e aceito em 14 de maio de 2008

$\left({ }^{2}\right)$ Estudante do Curso de Pós-Graduação em Entomologia - Universidade Federal do Paraná/UFPR, Caixa Postal 19020, Curitiba (PR). E-mail: melissajoelma@yahoo.com.br. (*) Autora correspondente.

( $\left.{ }^{3}\right)$ Departamento de Entomologia, Universidade Federal de Lavras/UFLA, Caixa Postal 3037,37200-000 Lavras (MG). E-mail: jcmoraes@ufla.br

(') Embrapa Florestas - Estrada da Ribeira, km 111, 83411-000 Colombo (PR). E-mail: edilson@cnpf.embrapa.br; iedeet@cnpf.embrapa.br 


\section{INTRODUÇÃO}

O pulgão-gigante-do-pinus Cinara atlantica (Wilson) (Hemiptera:Aphididae) está distribuído nos Estados das regiões Sul e Sudeste do Brasil provocando danos devido à sucção de seiva de ramos e caules de Pinus spp. (Penteado et al. 2000). Assim, torna-se necessário gerar alternativas de controle desta praga, entre as quais se destaca o manejo da adubação em viveiros, uma vez que a qualidade da planta hospedeira é a chave para a fecundidade dos insetos e os diferentes níveis de nutrição podem afetar a intensidade dos danos, o potencial e as estratégias de reprodução (CAMARGo e Moraes, 2006).

A resposta de insetos herbívoros para mudanças na qualidade da planta hospedeira varia dentre e entre as guildas de alimentação. A qualidade da planta hospedeira pode afetar estratégias reprodutivas como o tamanho do ovo, escolha da planta hospedeira para oviposição, entre outras estratégias. A medição da fecundidade provavelmente seja o melhor indicador dos efeitos da qualidade da planta hospedeira sobre a reprodução de herbívoros (AWMAcK e Leather, 2002).

O silício vem demonstrando importante papel na nutrição e proteção de algumas espécies vegetais. A falta do nutriente pode, portanto, resultar em diminuição da capacidade biológica da planta a resistir às condições adversas do meio ambiente (RAFI et al. 1997). Apesar das informações disponíveis sobre a utilização do silício em diversas plantas e culturas, poucos esforços têm sido dedicados a espécies arbóreas, como o eucalipto e pinus, que são espécies amplamente utilizadas nos reflorestamentos pelo Brasil (CARvalho et al. 2003). Jones e HANDRECK (1967) verificaram que este micronutriente pode ser absorvido por grande número de espécies de plantas sob condições de solo variáveis. De acordo com WeRner e Roth(1983), espécies do gênero Pinus são capazes de absorver largas quantidades de silício.

A resistência de plantas com nível adequado de silício em seus tecidos e sua relação com o ataque de insetos está sendo alvo de estudo por um número cada vez maior de pesquisadores no Brasil. Dentre esses estudos, podem se citar pesquisas com o pulgãoverde em trigo e sorgo, lagarta-do-cartucho em milho, broca-do-colmo em cevada, broca da cana-de-açúcar em cana, lagarta-do-colmo em arroz, entre outros (LiMA FILHO, 2005).

Acredita-se que o silício possa diminuir a incidência de doenças, o ataque de insetos além de maior proteção contra herbívoros, incluindo os insetos fitófagos. Esse processo ocorre devido à acumulação de silício abaixo da cutícula das folhas, que oferece resistência mecânica contra estes organismos (KORNDÖRFER, 1999).

Carvalho et al. (1999), avaliando o efeito do silício como indutor de resistência de plantas de sorgo ao pulgão-verde Schizaphis graminum (Rondani) (Hemiptera: Aphididae), em testes de preferência com e sem chance de escolha, verificaram redução na alimentação e na reprodução do pulgão-verde. Segundo Goussain et al. (2005), alterações químicas e a indução de resistência provavelmente estejam envolvidas na redução de desempenho de $S$. graminum, sem, entretanto, alterar seu período de alimentação. MorAes et al. (2004) estudaram a interação tritrófica trigo, S. graminum, inimigos naturais e verificaram que a aplicação de silício aumentou o grau de resistência das plantas de trigo, diminuindo a preferência do pulgão-verde em relação à testemunha.

Assim, o objetivo deste trabalho foi avaliar a preferência e a capacidade reprodutiva do pulgãogigante-do-pinus C. atlantica em plantas de P. taeda com e sem aplicação de silício.

\section{MATERIAL E MÉTODOS}

Dois bioensaios foram desenvolvidos em sala climatizada com temperatura de $20{ }^{\circ} \mathrm{C}$, umidade relativa de $70 \%$ e fotofase de 12 horas, no período de junho a agosto de 2006.

As mudas de $P$. taeda foram obtidas em viveiro comercial, com aproximadamente quatro meses de idade, contendo 22-3-8 $\mathrm{g} \mathrm{kg}^{-1}$ de NPK em seu substrato. Foram testadas duas doses de silício, utilizando-se como fonte o ácido silícico a $1 \%$, sendo os seguintes tratamentos: T1 - substrato padrão (sem aplicação de silício, somente $6 \mathrm{~mL}$ de água destilada); T2 - substrato padrão + uma dose de 0,01 gramas de silício por tubete (0,01 gramas diluídas em $6 \mathrm{~mL}$ de água destilada) e T3 - substrato padrão + quatro doses de 0,01 gramas de silício por tubete (quatro aplicações de 0,01 gramas diluídas em $6 \mathrm{~mL}$ de água destilada), com intervalo de cinco dias entre as aplicações. As doses foram parceladas e a solução aplicada via solo, ao redor das mudas em tubetes com capacidade de 21 gramas de substrato, para evitar fitotoxicidade nas mudas. As irrigações foram realizadas a cada dois dias, com 10 $\mathrm{mL}$ de água destilada. Após vinte dias da aplicação de silício, realizaram-se os testes de preferência e de capacidade reprodutiva com chance de escolha.

Preferência de $C$. atlantica em testes com chance de escolha em ramos de plantas de $P$. taeda, com e sem aplicação de silício 
Utilizaram-se como arena dez placas de Petri de $15 \mathrm{~cm}$ de diâmetro, forradas com papel filtro umedecido com água destilada, onde se distribuíram ramos de $P$. taeda com $2,5 \mathrm{~cm}$ de diâmetro, eqüidistantes entre si, correspondentes aos tratamentos 1, 2 e 3 . Em seguida, as placas foram cobertas com filme de PVC, com várias perfurações para entrada de ar. Simultaneamente às preparações das placas, selecionaram-se vinte adultos de $C$. atlantica (entre o $4^{\circ}$. e $5^{\circ}$. dia reprodutivo), para liberação no centro de cada placa. O delineamento experimental foi inteiramente casualizado, com três tratamentos e dez repetições.

As avaliações foram realizadas aos 40 e 90 minutos e às $4,12,18,24,36,48$ e 72 horas após a liberação dos insetos, anotando-se o número de pulgões que havia em cada ramo de pinus.

Preferência e capacidade reprodutiva de $C$. atlantica, em testes com chance de escolha, em plantas de $P$. taeda, com e sem aplicação de silício

Mudas de $P$. taeda em tubetes foram colocadas em gaiolas de PVC com $30 \mathrm{~cm}$ de diâmetro e $37 \mathrm{~cm}$ de altura, as quais foram utilizadas como arenas e onde os três tratamentos foram dispostos aleatoriamente. Para a confecção da arena, foi montada uma base em espuma revestida com papel kraft, onde os tubetes (tratamentos) foram inseridos. Vinte indivíduos adultos entre o $4 .^{\circ}$ e $5 .^{\circ}$ dia reprodutivo foram liberados no centro da arena (base de espuma revestida).

As avaliações foram realizadas no primeiro, segundo, terceiro, quarto e sétimo dia, estendendo-se este período por mais três semanas, totalizando um mês de avaliação. Foram observadas quais plantas eram escolhidas para alimentação e produção de ninfas de $C$. atlantica, sendo estas quantificadas e retiradas com o auxílio de um pincel.

Teor de silício em plantas de P. taeda, com e sem aplicação do nutriente

Para os dois testes, avaliou-se o teor de silício nas plantas antes da aplicação (0 dia) e aos 15,45 e 90 dias após a última aplicação do silício. A análise foi realizada em espectrofotômetro UV- visível, sendo as quantidades de silício (Si) transformadas em porcentagem, de acordo com expressão: \% Si = leitura x 0,045 .

Os dados de preferência e da capacidade reprodutiva dos bioensaios e de teores de silício foram submetidos à análise de variância (ANOVA) e as médias comparadas pelo teste de Tukey, a 5\% de probabilidade.

\section{RESULTADOS E DISCUSSÃO}

\author{
Preferência de $C$. atlantica em testes com chance de \\ escolha em ramos de plantas de $P$. taed $a, \operatorname{com}$ e \\ sem aplicação de silício
}

Foram detectadas diferenças no número de adultos de $C$. atlantica entre os tratamentos em todas as avaliações realizadas até as 36 horas (Tabela 1).

Nas avaliações aos 90 minutos e 4 horas, quando a maioria dos pulgões começou a se situar sobre algum ramo, o tratamento 3 (0,04 gramas de silício) diferiu dos demais, sendo assim, pouco preferido pelos afídeos. Já às 12, 18, 24 e 36 horas após o início do ensaio, os dois tratamentos com aplicação de silício passaram a diferir da testemunha, que estava com maior número de afídeos situados sobre seus ramos.

Após as 36 horas, houve um decréscimo no número de afídeos em todos os tratamentos, não sendo observado, na última avaliação, nenhum indivíduo nos ramos de pinus. Este fato possivelmente se deve à dessecação dos ramos, que perderam a turgescência e secaram. De acordo com López (1998), 36 horas da exposição de discos de folhas de melão é um tempo adequado para se avaliar mecanismos de resistência do tipo não-preferência para alimentação a pulgões. Contudo, CARVALHO et al. (1999) observaram diferenças para S. graminum em trigo tratado com silício após 63 horas, muito próximo das 72 horas recomendadas por Cruz et al. (1998).

No presente estudo, a maior diferença foi observada às 18 horas, de modo semelhante ao obtido por LóPEZ (1998), também verificando que as maiores diferenças entre plantas (folhas) suscetíveis e resistentes de melão a Aphis gossypii (Glover) (Hemiptera: Aphididae) foram às 18 horas.

Preferência e capacidade reprodutiva de $C$. atlantica, em testes com chance de escolha em plantas de $P$. taeda, com e sem aplicação de silício

Diferenças entre os tratamentos quanto à preferência foram significativas nas avaliações, com exceção da leitura realizada no $21 .^{\circ}$ dia (Tabela 2). Nas demais avaliações, as plantas referentes ao tratamento com maior aplicação de silício demonstraram não ser preferidas por indivíduos de C. atlantica, diferindo da testemunha.

Com relação à capacidade reprodutiva de $C$. atlantica, somente nas avaliações realizadas após o $4 .^{\circ}$ dia obtiveram-se valores significativos entre os tratamentos, sendo estes inferiores para plantas que receberam aplicação de silício, ou seja, não foram escolhidos para a deposição da prole (Tabela 3). 
Tabela 1. Número médio ( \pm erro-padrão) de adultos de Cinara atlantica em ramos destacados de plantas de Pinus taeda com e sem aplicação de silício, em diferentes períodos após sua liberação. $T=20{ }^{\circ} \mathrm{C}$; UR= $70 \%$; fotofase $=12$ horas

\begin{tabular}{lccc}
\hline \multirow{2}{*}{ Avaliação } & \multicolumn{3}{c}{ Adultos de C. atlantica/ramo de P. taeda } \\
\cline { 2 - 4 } & T1 - Testemunha & T2 - 0,01g/Si & T3 - 0,04g/Si \\
\cline { 2 - 4 } 40 minutos & $3,20 \pm 0,93 \mathrm{a}$ & $1,70 \pm 0,51 \mathrm{~b}$ & $1,20 \pm 0,71 \mathrm{~b}$ \\
90 minutos & $3,50 \pm 0,65 \mathrm{a}$ & $2,50 \pm 0,79 \mathrm{a}$ & $1,30 \pm 0,66 \mathrm{~b}$ \\
4 horas & $3,50 \pm 0,68 \mathrm{a}$ & $2,30 \pm 0,81 \mathrm{a}$ & $0,70 \pm 0,42 \mathrm{~b}$ \\
12 horas & $3,60 \pm 0,56 \mathrm{a}$ & $1,40 \pm 0,42 \mathrm{~b}$ & $0,40 \pm 0,30 \mathrm{~b}$ \\
18 horas & $3,60 \pm 0,56 \mathrm{a}$ & $1,10 \pm 0,60 \mathrm{~b}$ & $0,10 \pm 0,09 \mathrm{~b}$ \\
24 horas & $1,10 \pm 0,40 \mathrm{a}$ & $0,50 \pm 0,22 \mathrm{~b}$ & $0,40 \pm 0,21 \mathrm{~b}$ \\
36 horas & $1,20 \pm 0,32 \mathrm{a}$ & $0,30 \pm 0,09 \mathrm{~b}$ & $0,30 \pm 0,21 \mathrm{~b}$ \\
48 horas & $0,30 \pm 0,21 \mathrm{a}$ & $0,10 \pm 0,09 \mathrm{a}$ & $0,20 \pm 0,13 \mathrm{a}$ \\
72 horas & 0 & 0 & 0 \\
\hline Média & 2,0 & 1,2 & 0,5 \\
\hline
\end{tabular}

Médias seguidas de letras diferentes, nas linhas, diferem significativamente pelo teste Tukey $(\mathrm{p}=0,05)$.

Tabela 2. Número médio ( \pm erro padrão) de adultos de Cinara atlantica em plantas de Pinus taeda com e sem aplicação de silício, em diferentes períodos de avaliação após sua liberação. T: $20^{\circ} \mathrm{C}$; UR: 70\%; fotofase: 12 horas

\begin{tabular}{lccr}
\hline \multirow{2}{*}{ Avaliação } & \multicolumn{2}{c}{ Adultos de C. atlantica/muda de P. taeda } \\
\cline { 2 - 4 } & T1 - Testemunha & T2 - 0,01g/Si & T3 - 0,04g/Si \\
\cline { 2 - 4 } $1 .^{\circ}$ dia & $2,00 \pm 1,13 \mathrm{a}$ & $0,90 \pm 0,60 \mathrm{~b}$ & $1,10 \pm 0,50 \mathrm{~b}$ \\
$2 .^{\circ}$ dia & $1,60 \pm 0,73 \mathrm{a}$ & $1,00 \pm 0,63 \mathrm{ab}$ & $1,10 \pm 0,58 \mathrm{~b}$ \\
$3 .^{\circ}$ dia & $1,30 \pm 0,68 \mathrm{a}$ & $1,30 \pm 0,78 \mathrm{a}$ & $0,60 \pm 0,26 \mathrm{~b}$ \\
$4^{\circ}$ dia & $2,00 \pm 0,63 \mathrm{a}$ & $1,50 \pm 0,98 \mathrm{ab}$ & $1,10 \pm 0,50 \mathrm{~b}$ \\
$7 .^{\circ}$ dia & $1,90 \pm 0,68 \mathrm{a}$ & $1,00 \pm 0,39 \mathrm{ab}$ & $0,80 \pm 0,41 \mathrm{~b}$ \\
$14{ }^{\circ}$ dia & $1,60 \pm 0,57 \mathrm{a}$ & $1,50 \pm 1,17 \mathrm{a}$ & $0,20 \pm 0,13 \mathrm{~b}$ \\
$21 .^{\circ}$ dia & $0,70 \pm 0,39 \mathrm{a}$ & $0,30 \pm 0,29 \mathrm{a}$ & $0,30 \pm 0,15 \mathrm{a}$ \\
$28 .^{\circ}$ dia & $1,10 \pm 0,34 \mathrm{a}$ & $0,10 \pm 0,09 \mathrm{~b}$ & $0,10 \pm 0,09 \mathrm{~b}$ \\
\hline Média & 1,5 & 0,9 & 0,6 \\
\hline
\end{tabular}

Médias seguidas de letras diferentes, nas linhas, diferem significativamente pelo teste Tukey $(\mathrm{p}=0,05)$.

Tabela 3. Número médio ( \pm erro padrão) de ninfas/fêmea de Cinara atlantica em plantas de Pinus taeda com e sem aplicação de silício, em diferentes períodos de avaliação após sua liberação. T: $20{ }^{\circ} \mathrm{C}$; UR: $70 \%$; fotofase: 12 horas

\begin{tabular}{|c|c|c|c|}
\hline \multirow{2}{*}{ Avaliação } & \multicolumn{3}{|c|}{ Ninfas produzidas por C. atlantica } \\
\hline & T1 - Testemunha & $\mathrm{T} 2-0,01 \mathrm{~g} / \mathrm{Si}$ & $\mathrm{T} 3-0,04 \mathrm{~g} / \mathrm{Si}$ \\
\hline $1 .^{\circ}$ dia & $0,60 \pm 0,39 a$ & $0,0 \mathrm{a}$ & $0,20 \pm 0,19 a$ \\
\hline 2. ${ }^{\circ}$ dia & $0 \mathrm{a}$ & $0,20 \pm 0,19 a$ & $0,0 \mathrm{a}$ \\
\hline 3. ${ }^{\circ}$ dia & $0 \mathrm{a}$ & $0,20 \pm 0,19 a$ & $0,90 \pm 0,43 a$ \\
\hline $4 .^{\circ}$ dia & $0,40 \pm 0,30 \mathrm{a}$ & $0 \mathrm{a}$ & $0,10 \pm 0,09 a$ \\
\hline 7. ${ }^{\circ}$ dia & $3,40 \pm 1,51 a$ & $0,50 \pm 0,50 b$ & $0,0 \mathrm{~b}$ \\
\hline $14 .^{\circ}$ dia & $6,20 \pm 2,27 a$ & $3,50 \pm 2,86 b$ & $2,20 \pm 0,92 b$ \\
\hline $21 .^{\circ} \mathrm{dia}$ & $2,00 \pm 1,12 \mathrm{a}$ & $0,10 \pm 0,09 b$ & $0,0 \mathrm{~b}$ \\
\hline $28 .^{\circ} \mathrm{dia}$ & $8,30 \pm 2,57 a$ & $1,30 \pm 0,69 b$ & $0,30 \pm 0,29 b$ \\
\hline Média & 20,9 & 5,8 & 3,7 \\
\hline
\end{tabular}

Médias seguidas de letras diferentes, nas linhas, diferem significativamente pelo teste Tukey $(\mathrm{p}=0,05)$. 
Na última avaliação (28. ${ }^{\circ}$ dia), os tratamentos com aplicação de silício demonstraram causar algum efeito sobre a capacidade reprodutiva dos afídeos que produziram em média 1,30 e 0,30 ninfas, respectivamente, nos tratamentos 2 e 3 , enquanto afídeos criados em plantas sem aplicação de silício produziram em média 8,30 ninfas.

Com base na média total obtida nos tratamentos, fica evidente o efeito do nutriente sobre a capacidade reprodutiva do afídeo, onde plantas que não receberam aplicação de silício foram mais preferidas para alimentação e deposição da prole, quando comparadas a plantas que receberam aplicação.

Carvalho et al. (1999) e Moraes e Carvalho (2002) obtiveram efeitos semelhantes em estudos com adultos de $S$. graminum, cuja taxa reprodutiva variou em função da aplicação de silício e dos genótipos de sorgo, sendo praticamente o dobro nas folhas de plantas que não receberam aplicação de silício. BASAGLI et al. (2003) também obtiveram diferenças significativas na produção total de ninfas de S. graminum em plantas de trigo, sendo os valores praticamente o dobro em plantas sem aplicação de silício.

Verificou-se que o número médio de adultos em ramos destacados foi menor em relação aos valores obtidos para mudas em tubetes (Tabela 2). Tal diferença pode ser explicada pela dessecação dos ramos que pôde ter interferido nos resultados, visto que nas mudas em tubetes demoram mais para ocorrer tal dessecamento e acabam por permanecer mais adequadas aos insetos.
Os resultados sugerem que o silício acumulado nas plantas de pinus afetou tanto a preferência como a capacidade reprodutiva de C. atlantica. Provavelmente, tal fato decorreu da barreira mecânica formada na parede das células e/ou a presença de toxinas na seiva induzidas por este elemento, o que caracteriza a não-preferência por determinadas plantas (Hanisch, 1980). Estas acabam sendo menos utilizadas pelo inseto para alimentação e oviposição, quando comparadas às demais mantidas sob iguais condições. Contudo, outros estudos são necessários para melhor avaliação desta técnica alternativa no manejo de pulgões em viveiros de pinus.

\section{Teor de silício em plantas de P. taeda, com e sem aplicação do nutriente}

Comparando as análises de silício realizadas aos 15 dias antes da aplicação, com aquelas realizadas aos 45 e 90 dias após a última aplicação de silício, observou-se aumento significativo no teor de silício em plantas de P. taeda (Tabela 4). Esse aumento foi três vezes maior em plantas que receberam doses maiores de silício em relação à testemunha, aos 15 e 45 dias da sua aplicação. Resultados semelhantes foram constatados por vários autores em diferentes culturas (OKuda e TAKahashi, 1964; BenNetT, 1982; Hodson e Sangster, 1998; Carvalho et al. 1999; Goussain et al. 2002).

Tabela 4. Teor médio de silício $(\%) \mathrm{g} \mathrm{kg}^{-1}$ de acícula de plantas de Pinus taeda com e sem aplicação de silício

\begin{tabular}{|c|c|c|c|c|c|}
\hline \multirow{2}{*}{ Tratamentos } & \multirow{2}{*}{ Sem sílicio } & \multicolumn{3}{|c|}{ Dias após aplicação de silício } & \multirow{2}{*}{ Média } \\
\hline & & 15 & 45 & 90 & \\
\hline & & & 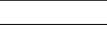 & & \\
\hline T1 - Testemunha & $0,3 a$ & $0,43 a$ & $0,62 \mathrm{a}$ & $0,25 a$ & $0,40 \mathrm{a}$ \\
\hline $\mathrm{T} 2-0,01 \mathrm{~g} / \mathrm{Si}$ & $0,3 a$ & $0,97 b$ & $0,81 \mathrm{ab}$ & $0,57 b$ & $0,66 a$ \\
\hline $\mathrm{T} 3-0,04 \mathrm{~g} / \mathrm{Si}$ & $0,3 a$ & $1,35 b$ & $0,94 b$ & $0,64 b$ & $0,80 \mathrm{~b}$ \\
\hline
\end{tabular}

Médias seguidas de letras diferentes, nas linhas, diferem significativamente pelo teste Tukey $(\mathrm{p}=0,05)$.

Os resultados demonstraram que a aplicação de silício influenciou a preferência e a capacidade reprodutiva de $C$. atlantica, constituindo-se uma das causas de resistência de $P$. taeda ao pulgão-gigante-do-pinus, uma vez que houve preferência dos afídeos a plantas sem aplicação do silício. Pode-se sugerir que ocorra em razão da formação de uma barreira mecânica, criada a partir da deposição de silício e/ou por alguma substância produzida pelas plantas como resposta à presença deste mineral.

\section{CONCLUSÕES}

1. Plantas de $P$. taeda são capazes de absorver o silício e sua aplicação induz resistência a plantas de pinus ao pulgão-gigante-do-pinus C. atlantica, reduzindo a preferência e a capacidade reprodutiva do adulto.

2. A melhor dose entre os tratamentos foi de $0,04 \mathrm{~g}$ de silício por tubete, em que C. atlantica demonstrou não-preferência e baixa produção de ninfas. 


\section{AGRADECIMENTOS}

Ao Dr. Renato Antônio Dedecek, Pesquisador do Laboratório de Solos - Embrapa Florestas, pelo auxílio nas análises nutricionais. À CAPES, Coordenação de Aperfeiçoamento de Pessoal de Ensino Superior, pela concessão da bolsa e ao Laboratório de Entomologia - Embrapa Florestas pelo espaço concedido para a execução deste trabalho.

\section{REFERÊNCIAS}

AWMACK, C.S.; LEATHER, S.R. Host plant quality and fecundity in herbivorous insects. Annual Review of Entomology, London, v.47, n.817-844, 2002.

BASAGLI, M.A.B.; MORAES, J.C.; CARVALHO, G. A.; CARVALHO, C. E.; GONÇALVES-GERVÁSIO, R. D. C. R. Efeito da aplicação de silicato de sódio na resistência de plantas de trigo ao pulgão-verde Schizaphis graminum (Rond., 1852) (Hemiptera: Aphididae). Neotropical Entomology, Vacaria, v.32, n.4, p.659-663, 2003.

BENNETT, D.M. An ultrastructural study on the development of silicified tissue in the leaf tip of barley (Hordeum sativum Jess). Annals of Botany, Oxford, v.50, p.229-237, 1982.

CAMARGO, J.M.M; MORAES, J.C. Efeito da aplicação de silício em Pinus taeda (Pinaceae) na preferência alimentar do pulgãogigante-do-pinus Cinara atlantica (Hemiptera: Aphididae). In: CONGRESSO BRASILEIRO DE ENTOMOLOGIA, 21., 2006, Recife, PE. (Cd-rom)

CARVALHO, R.; NETO, A.E.F.; CURI, N.; RESENDE, A.V. Absorção e translocação de silício em mudas de eucalipto cultivadas em Latossolo e Cambissolo. Ciência e Agrotecnologia, Lavras, v.27, n.3, p.491-500, 2003.

CARVALHO, S.K., MORAES, J.C.; CARVALHO, J.G. Efeito do silício na resistência do sorgo (Sorghum bicolor) ao pulgãoverde Schizaphis graminum (Rondani) (Homoptera: Aphididae). Anais da Sociedade Entomológica do Brasil, Londrina, v.28, p.505-510, 1999.

CRUZ, I.; VENDRAMIN, J.D.; OLIVEIRA, A.C. Determinação do período de avaliação de não-preferência de sorgo ao pulgãoverde, Schizaphis graminum (Rond.) (Homoptera: Aphididae). Anais da Sociedade Entomológica do Brasil, Londrina, v.27, p.299-302, 1998.

GOUSSAIN, M.M.; MORAES, J.C.; CARVALHO, J.G.; NOGUEIRA, N.L.; ROSSI, M.L. Efeito do silício em plantas de milho no desenvolvimento biológico da lagarta-do-cartucho Spodoptera frugiperda (J.E. Smith) (Lepidoptera: Noctuidae). Neotropical Entomology, Vacaria, v.31, p.305-310, 2002.

GOUSSAIN, M.M.; PRADO, E.; MORAES, J. C. Effect of silicon applied to wheat plants on the biology and probing behaviour of the greenbug Schizaphis graminum (Rondani) (Hemiptera:Aphididae). Neotropical Entomology, Vacaria, v.34, n.5, p.807-813, 2005.
HANISCH, H.C. Zun einfluss der stickstoffdungung und vorbeugender spritzung von natronwasser glas zu weizenpflanzen auf deren widerstandsfahigkeit gegen getreideblattlause. Kali-Driefe, Berlin, v.15, p.287-296, 1980.

HODSON, M.J. and SANGSTER, A.G. Mineral deposition in the needles of white spruce [Picea glauca (Moench.) Voss]. Annals of Botany, Oxford, v.82, p.375-385, 1998.

JONES, L.H.P. and HANDRECK, K.A. Silica in soils, plants, and animals. Advances in Agronomy, New York, v.19, p.107149, 1967.

KORNDÖRFER, G.H.; GASCHO, G.J. Avaliação de fontes de silício para o arroz. In: CONGRESSO NACIONAL DE ARROZ IRRIGADO, 1., Pelotas. Anais... Pelotas, 1999. p.313-316, 1999.

LIMA FILHO, O.F. O silício e a resistência das plantas ao ataque de fungos patogênicos. Disponível em: http:// www.embrapa.br/noticias/artigos/folder.2005 - artigo Review of recent research. Revista IL RISO v.28, p.235-253, 2005. Acesso em 14/05/2006.

LÓPEZ, B. M. Evaluación y caracterización de las resistencias en melón a Aphis gossypii Glover y a la transmisión no persistente de virus por este vector. 1998. 195 p. Tesis Doctoral Universidad Politécnica de Madrid, Escuela Técnica Superior de Ingenieros Agrónomos, Madrid. 1998.

MORAES, J. C.; CARVALHO, S.P. Indução de resistência em plantas de sorgo Sorghum bicolor (L.) Moench. ao pulgão-verde Schizaphis graminum (Rond., 1852) (Hemiptera:Aphididae) com a aplicação de silício. Ciências e Agrotecnologia, Lavras, v.26, n.6, p.1185-1189, 2002.

MORAES, J.C.; GOUSSAIN, M.M.; BASAGLI, M.A.B. Silicon influence on the tritrophic interaction: wheat plants, the greenbug Schizaphis graminum (Rondani) (Hemiptera: Aphididae), and its natural enemies, Chrysoperla externa (Hagen) (Neuroptera: Chrysopidae) and Aphidius colemani Viereck (Hymenoptera: Aphidiidae). Neotropical Entomology, Vacaria, v.33, n.5, p.619-624, 2004.

OKUDA, A.; TAKAHASHI, E. The role of silicon. In: HOPKINSIB, J. The mineral nutrition of the rice plant. Proceedings of Symposium International Rice Research, p.123-146, 1964.

PENTEADO, S.R.C.; TRENTINI, R.F.; IEDE, E.T.; FILHO, W.R. Ocorrência, distribuição, danos e controle de pulgões do gênero Cinara em Pinus spp. no Brasil. Revista Floresta, Curitiba, v.30, n.1/2, p.55-64, 2000.

RAFI, M.M.; EPSTEIN, E.; FALK, R.H. Silicon deprivation causes physical abnormalities in wheat (Triticum aestivum L.). Journal Plant Physiology, London, v.151, p.497-501, 1997.

WERNER, D. \& ROTH, R. Silica metabolism. In: Lauchli, A.; Bieleski, R. L. Encyclopedia of plant physiology. New Series, Berlin: Springer-Verlag, v.15, p.682-694, 1983.

WILSON, H.F. Some new Lachnids of the genus Lachniella (Homoptera: Hemiptera). The Canadian Entomologist, Ottawa, v.51, n.1/2, p.18-22, 41-47, 1919. 